\title{
Integrating Renewable Energy Sources to an Urban Building in India: Challenges, Opportunities, and Techno-Economic Feasibility Simulation
}

\author{
Y. V. Pavan Kumar ${ }^{1}$ • Bhimasingu Ravikumar ${ }^{1}$
}

Received: 20 October 2014 / Accepted: 28 May 2015 /Published online: 23 July 2015

(C) Springer Science+Business Media Singapore 2015

\begin{abstract}
Microgrids deployment is primarily envisioned to meet the energy needs of remote areas due to inaccessibility of utility power. But, due to the recent globalization epoch, the rural and remote areas in the world are merging into urban communities and creating huge burden on the utility grid. Hence, the microgrids design focus has been shifting towards urban communities. Hybrid power systems are becoming a popular way in the design of microgrids by using locally available renewable energy sources (RES). This compensates the global depletion of conventional fossil fuel based utility grid energy. At this point of time, it is very important to examine the adoptability of those recent evolutions for a specific user location. With this intent, this paper presents various prospects in terms of challenges, opportunities, and technoeconomic feasibility analysis for the integration of various RES to an existing urban building power system. The analysis is done by considering practical data of an enterprise building located in India. Various RES such as, photovoltaics, parabolic troughs, and wind energy are considered to form the microgrid. The simulation results increase the faith on the designed architecture by projecting an average cost savings of $27.55 \%$ /day on the energy utilization with 5.97 years of return on investment. This analysis can be adoptable for any large scale urban community buildings such as financial districts, universities, residential greater communities, and industries.
\end{abstract}

Y. V. Pavan Kumar

ee14resch01008@iith.ac.in

Bhimasingu Ravikumar

ravikumar@iith.ac.in

1 Department of Electrical Engineering, Indian Institute of Technology Hyderabad (IITH), Hyderabad, India
Keywords Microgrids $\cdot$ Hybrid Power Systems (HPS) · Renewable Energy Sources (RES) · Wind Power (WP) · Solar Photovoltaic (PV) · Solar Parabolic Troughs (PT)

Nomenclatur
chu
ptu
lpt
lgt
ser
lbe
pum
$p v a$
$w t g$
$d g s$
$c h r, d s r$
$i$
$r_{i}(t)$
$\tau$
$\theta_{\text {in }}(t)$
$\theta_{\text {out }}(t)$
$\Delta \theta_{\text {in }}$
$\theta_{i}^{\min }$
$\theta_{i}^{\max }$
$\Psi_{i}$
$\Phi_{i}$
$S(t)$
$T_{i}$
$x_{i}(t)$

Air conditioning unit

Chiller unit

Parabolic trough unit

Laptop unit

Lighting unit

Server unit

Laboratory equipment

Pump load

PV array

Wind turbine generator

Diesel generator

Charging, discharging

Indicates type of equipment

State of an equipment $i$ at time $t$ (ON/OFF)

Set of indices in the time axis scheduling

Inside temperature at time $t$

Outside temperature at time $t$

Small change in $\theta_{i n}(t)$ at time $t$.

Minimum temperature of the $i^{\text {th }}$ unit

Maximum temperature of the $i^{\text {th }}$ unit

Warming/cooling of OFF state of $i^{\text {th }}$ equipment.

Warming/cooling of ON state of $i^{\text {th }}$ equipment.

Set of equipment considered from available list.

Time period of operation of $i^{\text {th }}$ equipment.

Denotes startup of $i^{\text {th }}$ equipment at time $t$.

$$
x_{i}(t)= \begin{cases}1 & \text { startup } \\ 0 & \text { otherwise }\end{cases}
$$


$y_{i}(t) \quad$ Denotes shutdown of $i^{t h}$ equipment at time $t$

$$
y_{i}(t)= \begin{cases}1 & \text { shutdown } \\ 0 & \text { otherwise }\end{cases}
$$

$D_{i}^{m s t}$

Max consecutive operating time of $i^{\text {th }}$ equipment.

$D_{i}^{r o t} \quad$ Desired operating time of $i^{\text {th }}$ equipment.

$\varepsilon_{i}(t) \quad$ Earlier operation time of $i^{t h}$ equipment.

$L t_{i}(t) \quad$ Latest operation time of $i^{\text {th }}$ equipment.

$M u_{i} \quad$ Minimum up time of $i^{t h}$ equipment.

$M d_{i} \quad$ Minimum down time of $i^{t h}$ equipment.

$N \quad$ Number of units.

$n, k \quad$ Analog, discrete time instants.

$e_{i}(t) \quad$ Energy storage level of $i^{t h}$ equipment at time $t$.

$C h_{i}(t) \quad$ Charged power of $i^{t h}$ equipment at time $t$.

$\bar{C}_{i} \quad$ Discharge power from $i^{\text {th }}$ equipment.

$E_{i} \quad$ Energy level indication of $i^{\text {th }}$ equipment.

$P_{i}(t) \quad$ Rated power of $i^{t h}$ equipment at time $t$.

\section{Introduction to Microgrids}

Electrical energy has become a major source for the sustainability of human life. As, the population is being increased, dependability on electricity is also increased. The statistics estimates that the world population may reach to 8 billion by 2020 and this increase is typically in developing countries. This necessitates the expansion of utility grid to meet this ever-increasing demand [1]. In the present energy sector, the conventional grid is overloaded and faces problems of fossil fuel depletions, less efficient and ageing machinery at generation; poor efficiencies in transmission and distribution; high installation and operational costs at distribution. Besides, steady evolution of the regulatory and functional changes of electric utilities have led to a new theme of local power generation using RES at distribution level to form flexible, modular, and task-oriented systems, known as microgrids [2].

Microgrids are being formed as an aggregation of various distributed resources and storage systems typically located at the site of use and seamlessly integrated with the utility grid. These uses conventional fuels such as diesel, natural gas, and/ or RES such as solar, biogas, hydel, wind, hydrogen, etc. The critical operation of the microgrid derives from its appearance to the utility grid as a single and self controlled entity called island operation or integrated and running in parallel with national grid called grid mode operation. The major application of RES based microgrids are to supply the energy needs of a 'green building'. These are meant for optimal use of energy resources by reducing wastages [3, 4].

\section{Literature Review}

The literature mentioned below gives some of the state of the art works done on the general design and implementation of microgrids. This paper discusses the challenges and opportunities to deploy microgrids and presents the feasibility analysis for the adoptability of microgrids in the Indian scenario with a practical case study.

Li et al. [5] presented latest advancements in microgrids development in view of dispatch and control schemes. Adoptability of communication technology, load management technology, and protection strategies to microgrid were discussed. Hong Zhang et al. [6] presented an economic optimization model to minimize energy purchase costs for distribution system operators by using interior point method. Wang et al. [7] presented possible operating scenarios for standalone microgrids by considering the daily patterns of load and wind profiles using clustering techniques. Lu Zhang et al. [8] presented a deterministic method based on DIRECT algorithm for optimum sizing of the HPS by minimizing system investment cost. Mathematical modelling was done based on the cost consideration for all types of load. Mohsenian et al. [9] presented an automatic framework for scheduling residential loads. This realizes a trade-off between waiting time for the household appliances operation and minimizing the energy usage cost. Emiliano et al. [10] presented an optimal power flow for an unbalanced microgrid. This uses non-convex optimization with an objective function of low power distribution losses. Bansal et al. [11] presented an optimization procedure for the calculation of optimum sizing of HPS by total cost minimization. Kellogg et al. [12] presented the design of WP, PV, and hybrid WP/PV standalone power generating systems. A numerical algorithm was developed to find the optimal generation capability and storage facility required. Saif et al. [13] presented two-layer model based on optimal power flow and particle swarm optimization to obtain the optimum capacity requirements of distributed energy resources and their allocation with an imperfect grid connection. Pavlos et al. [14] presented methods for the optimum integration of distributed energy units based on the analysis of current and future trends. Omar et al. [15] presented the design, planning, and operation of a RES based microgrid with minimum lifecycle cost while considering environmental emissions.

\section{Challenges in Indian Energy Scenario}

Microgrid concept provides a unique opportunity in Indian context due to unique requirements, spiraling energy needs, and inherent challenges. Transmission losses, energy shortage, rural electrification issues brings various technoeconomic challenges, which affects reliability and efficiency of presently existing grid network. On the other hand, 35$40 \%$ of the rural India is still not electrified. Government of India (GOI) is gearing up to address these challenges. Ambient conditions, solar insolation, weather patterns, biomass availability brings RES to forefront. The ambitious 
government energy missions, regulations on usage of fossil fuel energy, availability of attractive subsidies for renewable energy are the key drivers for microgrid installations across India.

The installed capacity by April 2014 is 245.394 GW [16]. Figure 1 shows the contribution of various energy sources. From the normal and peak energy statistics shown in Figs. 2 and 3, it can be observed that there is a dire need for enhancing generation capacities to fill the demand and supply gap [17].

Table 1, gives the present stage of demand and supply parity in India. It can be seen that the southern region is suffering badly in both normal and peak conditions among others. Hence, this paper focuses on the development and techno-economic feasibility analysis of RES based microgrids deployment in south India by considering a practical case.

\section{Key Challenges to Specific Stakeholders}

The key challenges for different stakeholders to deploy microgrids are as follows $[18,19]$.

\section{Challenges for Utilities and Customers}

- Reducing T \& D and unit cost by RES integration.

- Peak load management by installing distribution and substation management systems.

- Increase in grid self-healing and visibility.

- More viable solutions design for rural electrification.

- Improve supply reliability to all-no power cuts.

- Improving supply quality with less voltage stabilizers.

- Enhanced choice for customers including RES power.

- 'Prosumer' (producer \& consumer) enablement.

- Use of advanced metering infrastructures.

\section{Challenges for Government and Regulators}

- Achieving financially strong utilities.

- Reducing the intensity of emissions.

- Tariff system modernization for satisfied consumers.

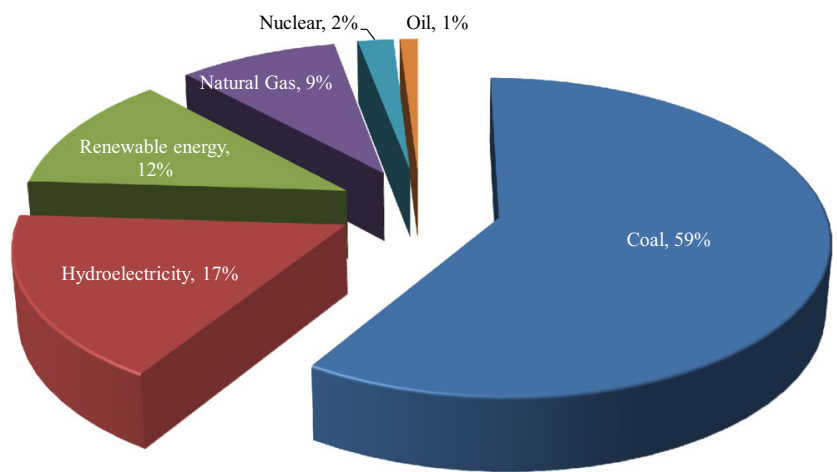

Fig. 1 Sources of electricity in India as per installed capacity

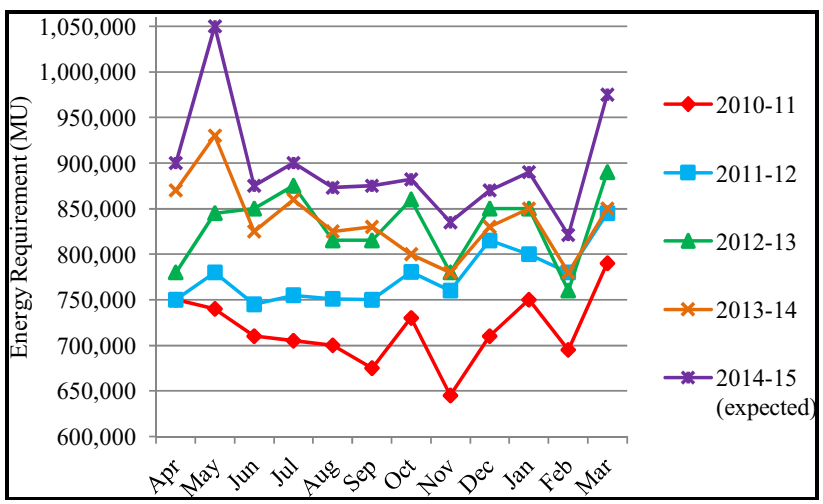

Fig. 2 Base energy requirement in India over last 5 years

- Handling large untapped potential.

- Strengthening the energy security policies.

\section{Opportunities in Indian scenario}

It is realized that, electrifying the rural areas completely is a distant dream of India besides the ever increasing energy needs of urbanization. GOI is actively promoting the alternate energy resources for this purpose. India has many potential opportunities as mentioned below to implement distributed generation and microgrid technologies. As of now, projects such as PV, micro hydro, and small biomass gasifiers have been implemented in off grid mode. Wind and cogeneration projects have been promoted mostly in grid connected mode.

\section{Ecological Opportunities}

India is majorly located on the equatorial sun belt of the earth, thus getting plentiful energy radiations from the sun. It gets about 5000 trillion $\mathrm{kWh} /$ year energy equivalent over solar radiations. In majority part of India, clear sunny climate is available 275-300 days in a year. The global radiations vary from 1600 to $2200 \mathrm{kWh} / \mathrm{m}^{2}$ annually. The average solar radiation over India is $5.5 \mathrm{kWh} / \mathrm{m}^{2} /$ day. Assuming conversion

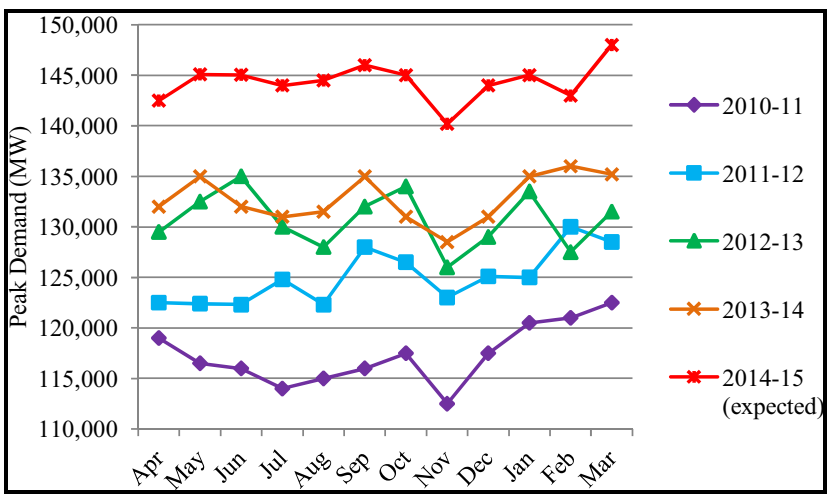

Fig. 3 Peak energy requirement in India over last 5 years 
Table 1 Energy statistics in India as on May 2014

\begin{tabular}{|c|c|c|c|c|c|c|c|c|}
\hline \multirow[t]{3}{*}{ Region } & \multicolumn{4}{|c|}{ Normal condition } & \multicolumn{4}{|l|}{ Peak condition } \\
\hline & \multirow[t]{2}{*}{ Demand (MU) } & \multirow[t]{2}{*}{ Supply (MU) } & \multicolumn{2}{|c|}{ Surplus(+)/Deficit(-) } & \multirow[t]{2}{*}{ Demand (MW) } & \multirow[t]{2}{*}{ Supply (MW) } & \multicolumn{2}{|c|}{ Surplus(+)/Deficit (-) } \\
\hline & & & (MU) & $(\%)$ & & & (MW) & $(\%)$ \\
\hline Northern & 328943 & 318836 & -10107 & -3.1 & 47570 & 46899 & -671 & -1.4 \\
\hline Western & 288062 & 289029 & 967 & 0.3 & 45980 & 52652 & 6672 & 14.5 \\
\hline Southern & 298180 & 260366 & -37814 & -12.7 & 41677 & 32423 & -9254 & -22.2 \\
\hline Eastern & 118663 & 114677 & -3986 & -3.4 & 17608 & 17782 & 174 & 1.0 \\
\hline North-Eastern & 14822 & 12247 & -2576 & -17.4 & 2542 & 2214 & -326 & -12.9 \\
\hline All India & 1048670 & 995155 & -53516 & -36.3 & 155377 & 151970 & -3405 & -21 \\
\hline
\end{tabular}

efficiency of $11 \%$, PV can produce $1 \mathrm{MWh}$ energy per day on just 0.118 hectares of land [20].

\section{South Indian Scenario}

The type of available RES affects the economics and behaviour of the microgrid. Solar data indicates the quantity of solar radiation that hits earth's surface in a year. The southern part of India faces a mix of tropical dry and wet climate (http://www. hyderabadplanet.com/hyderabad-weather.html). The considered case study application in this paper is located at $17.37^{\circ}$ latitude (North), $78.47^{\circ}$ longitude (East), and at $536 \mathrm{~m}$ of altitude in south India (http://en.wikipedia.org/wiki/ Geography_of_Hyderabad). This place has an average solar radiation of $5.34 \mathrm{kWh} / \mathrm{m}^{2}$ with maximum radiation of more than $6 \mathrm{kWh} / \mathrm{m}^{2}$ as shown in Fig. 4. Wind profile is also quite appreciable at this location as shown in Fig. 5 [21]. The average wind velocity is $4.141 \mathrm{~m} / \mathrm{s}$.

From this wind and solar data, it can be observed that June, July, August and September is undergoing less solar resource, where the wind resource is more and compensates it. This makes total energy availability as almost constant throughout the year. So, the conventional power systems can be augmented by the hybrid energy of RES to get rid of fossil fuel depletions. RES has other inherent advantages such as no

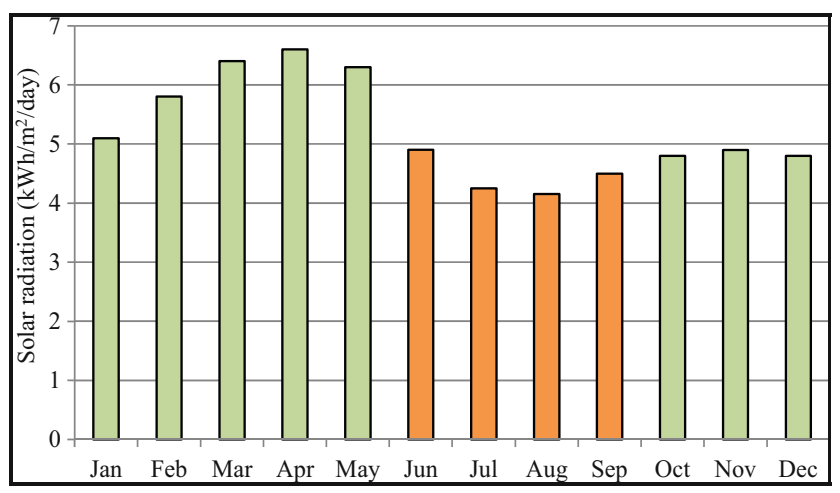

Fig. 4 Profile of solar radiations environmental pollution, can be located nearer to loads, which leads to elimination of T\&D losses and investment costs.

\section{Government Initiatives}

The demand and supply gap has forced the authorities to look for the development of captive power plants at the load centers. These plants maybe formed by diesel generators or RES or combination of both. The urban buildings such as financial districts, greater communities, industries, universities, and other commercials are the major contributors of grid demand, which requires onsite power generation to reduce burden on utility.

India has abundant RES energy availability and initiated many programs for deploying RES systems at the site of use. India has an exclusive ministry for RES energy development named "ministry of non-conventional energy sources (MNES)" formed in 1992 and later has got changed to "ministry of new and renewable energy (MNRE)" in 2006. From the day of its formation, it has launched very ambitious policies on RES systems. With various promotional offers initiated by MNRE, substantial progress is being made in the power sector. It has announced a goal of $20 \mathrm{GW}$ solar energy installations by $2020,100 \mathrm{GW}$ by 2030 , and $200 \mathrm{GW}$ by 2050 . MNRE encourages microgrid installations with the below subsidy schemes [18].

\section{The Electricity Act-2003}

The Electricity Act-2003 has given a push to distributed energy generation specifically in the rural electrification. This specifies distributed energy generation and supply over standalone conventional and RES systems [22].

\section{National Electricity Policy—2005}

In extension to electricity act-2003, electric policy-2005 recommends under the rural electrification to deliver a reliable 


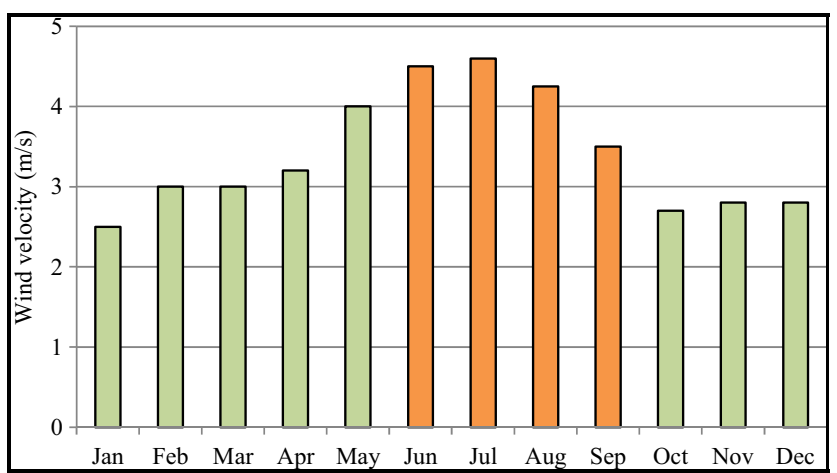

Fig. 5 Profile of wind velocity

electrification system, where the conventional grid is not feasible to extend and decentralized distributed generation facilities (conventional or RES) together with local distribution system are provided [23].

\section{Diesel Abatement Scheme}

The GOI has introduced attractive diesel abatement schemes which promote the augmentation of diesel powered captive plants with RES.

- For non-profit making buildings such as government, domestic, universities, and institutions, up to $40 \%$ of the total installation cost will be borne by GOI.

- It is reduced to $30 \%$ for a profit making organization.

\section{Solar Energy Scheme}

GOI has announced attractive financial subsidy schemes for installation of RES at building level. Financial funding as per the following rules are available for different consumers.

- General category states for all users: $5 \%$ interest loan on $80 \%$ benchmark cost or $30 \%$ capital subsidy.

- Special category states for domestic and non-commercial users (not availing accelerated depreciation): $5 \%$ interest loan on $80 \%$ benchmark cost or $60 \%$ capital subsidy.

- Special category states for commercial user category (availing accelerated depreciation): $5 \%$ interest loan on $80 \%$ benchmark cost or $30 \%$ capital subsidy.

\section{Other Schemes}

Two schemes named, "Remote Village Electrification Scheme and the Rajiv Gandhi Grameen Vidyutikaran Yojna" will provide up to $90 \%$ capital subsidy for rural electrification that uses decentralized distributed energy generation systems based on non-conventional and or conventional fuels [24, 25].
Added to above mentioned schemes, regulatory measures to promote the renewable energy are being framed. The MNRE is working on the regulations on 'minimum renewable energy content' in commercial buildings and is planning to introduce it in the near future. This bill would mandate commercial establishments, universities, industries, residential complexes, and government buildings to embrace renewable energy generated at the site thus promoting microgrid development in India. Added to this regulatory measures from GOI, various state governments are also planning to introduce the 'green cess' based on the total $\mathrm{kWh}$ consumption of the facility (e.g., Gujarat Green Cess Act, 2011). The accumulated money is earmarked for development of renewable energy research with a thrust on microgrids at the building level.

\section{Implementation of Microgrids for Indian Buildings-Feasibility Analysis Through a Case Study}

Economy and reliability are the major constraints in the design of microgrid schemes. Moreover, proper considerations of microgrid constituents will lead to the optimal system operation by reducing the overall energy cost. With this intent, this paper emphases on the development of an economic microgrid architecture for a building that is a part of an urban electrification. A realistic case of an enterprise building is considered to examine the effectiveness of the RES based microgrid deployment. The overall building power system includes various constituents such as chillers, heating ventilation air conditioning (HVAC), servers, laptops, pumps, lab equipment, lighting, PV, PT, WP, and diesel generators.

\section{Practical Case Study Description}

To perform feasibility analysis of microgrid formation, the real-time data of an IT business unit placed at Hyderabad, southern part of India is considered. The building has a maximum load demand of $920 \mathrm{~kW}$ which is segregated into priority and deferrable loads as shown in Table 2 .

Priority load is the electrical demand that the power system should serve at a specific time in a day. Deferrable loads can be met anytime in a time interval. Figures 6 and 7 shows profile of the priority and deferrable loads respectively.

Currently, the building is being supplied from utility grid along with a backup diesel generator set. The availability of RES at this site is described in Section 3.1.1. The schematic of retrofitted building power system designed in this paper is shown in Fig. 8. It has four wings namely local energy, grid supply, priority load, and deferrable load. The local energy consists of PV, WP, PT, and diesel generator resources. The grid supply wing shows utility grid interface to building. 
Table 2 Building load segregation

\begin{tabular}{llll}
\hline Load category & Load type & \multicolumn{2}{l}{ Demand $(\mathrm{kW})$} \\
\hline Priority & Elevators & 63 & Total $=479 \mathrm{~kW}$ \\
& Lighting & 110 & \\
& UPS & 288 & \\
Others & 18 & \\
Deferrable & AHU & 54 & Total = 441 kW \\
& Pump load & 72 & \\
& HVAC & 279 & \\
& Others & 36 & \\
Maximum demand of the building & & $920 \mathrm{~kW}$ \\
\hline
\end{tabular}

\section{Modeling of the Microgrid System}

Various constituents in the microgrid system are modeled individually as given below and integrated for the overall system operation. The modeling of loads and energy sources is based on their operation with respect to the outside and inside building temperatures.

\section{Solar Thermal Unit Through HVAC and PT}

Solar thermal unit consists of PT concentrators, receiver tubes, hot water header, automatic tracking systems, valves and controls. Figures 9, 10, and 11 gives the schematics of PT array, cooling system, and vapour absorption machine (VAM) respectively. PT concentrator shall concentrate the sun light and generate high temperature hot water. The header shall be used as temperature reservoir. The PT concentrators shall be tracked automatically with help of a drive and gear motor, but the focus shall be fixed at receiver line. Receiver tubes shall be connected to the hot water supply and return headers by means of flexible hoses. Hot water at $165^{\circ} \mathrm{C}$ shall be generated by harnessing solar thermal energy. In the expansion tank, the hot water circulation is pressurized via $\mathrm{N}_{2}$ blanketing.

From the expansion tank, the hot water of $165{ }^{\circ} \mathrm{C}$ is pumped to VAM and is returned to $145^{\circ} \mathrm{C}$ from VAM to PT

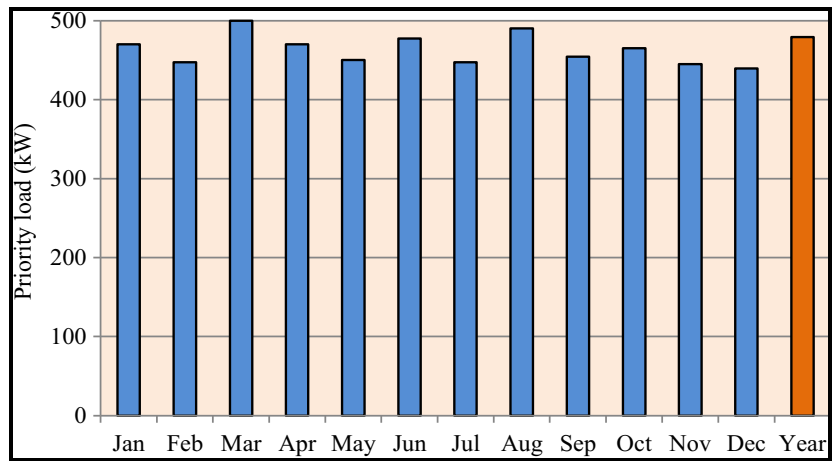

Fig. 6 Priority load profile in a year

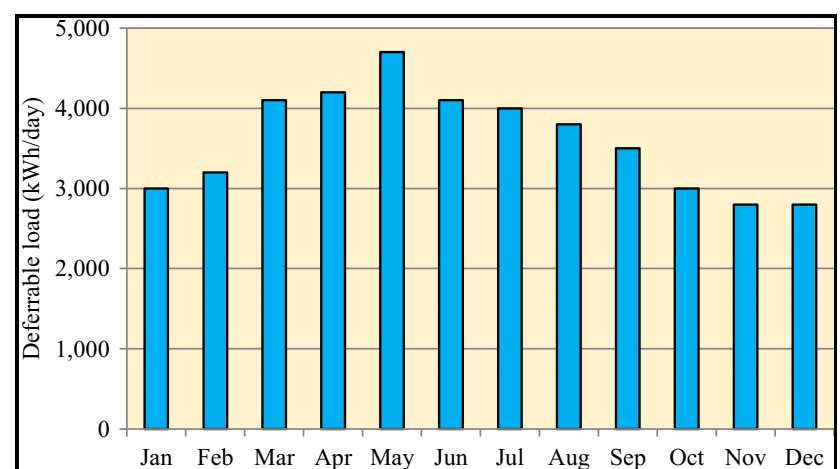

Fig. 7 Deferrable load profile in a year

concentrators. Chilled water at about $7{ }^{\circ} \mathrm{C}$ is circulated from the electrical chillers through a common header to the air handling unit (AHU). Thereafter, the chilled water is returned from AHU to chiller via common return header. A tapping of $12{ }^{\circ} \mathrm{C}$ is taken from chilled water return line and given as an input to VAM. It shall supply chilled water at $10^{\circ} \mathrm{C}$ which will be sent to the return line. Thus the VAM will act as a precooler. The balance cooling shall be done by chillers. These shall cater to air-conditioning requirement even when solar radiation is not sufficient during unfavorable weather [26, 27]. This integrated system maximizes the use of solar thermal energy to meet the necessary cooling load.

The AC unit, Chiller, and PT works based on the outside and inside temperatures of the building. The modeling of these units is based on (1)-(6) and Table 3 .

The optimal function is given as (1);

$r_{a c u}(t)+r_{c h u}(t)+r_{p t u}(t)=1 \quad \forall t \in T_{i}$

The temperature of the units at time $\mathrm{t} \sec$ is given by (2).

$\theta_{\text {in }}(t)=\theta_{\text {in }}(t-1)$

$$
+\tau\left[\psi_{i} S(t)-\varphi_{i} r_{i}(t)+\Gamma_{i}\left(\theta_{\text {out }}(t)-\theta_{\text {in }}(t)\right)\right]
$$

With respect to the constraints (3)-(5):

$r_{i}(t)= \begin{cases}0 \text { or } 1 & \text { if } t \in T_{i} \\ 0 & \text { if } t \notin T_{i}\end{cases}$

$\theta_{i}^{\min }(t) \leq \theta_{i}(t) \leq \theta_{i}^{\max }(t), \quad \forall t \in T_{i}$

$r_{i}(1)= \begin{cases}1 & \text { if } \theta_{i}(0)>\theta_{i}^{\max } \\ 0 & \text { if } \theta_{i}(0)<\theta_{i}^{\min }\end{cases}$

The effect of outside temperature on the inside temperature ( $\Gamma \mathrm{i})$ is given as (6);

$\Gamma_{i}=\frac{\Delta \theta_{\text {in }}}{\left(\theta_{\text {out }}-\theta_{\text {in }}\right)} \times \Delta t$

Where, ' $i$ ' represents $a c u / c h u / p t u$. 
Fig. 8 Integrated building microgrid system schematic

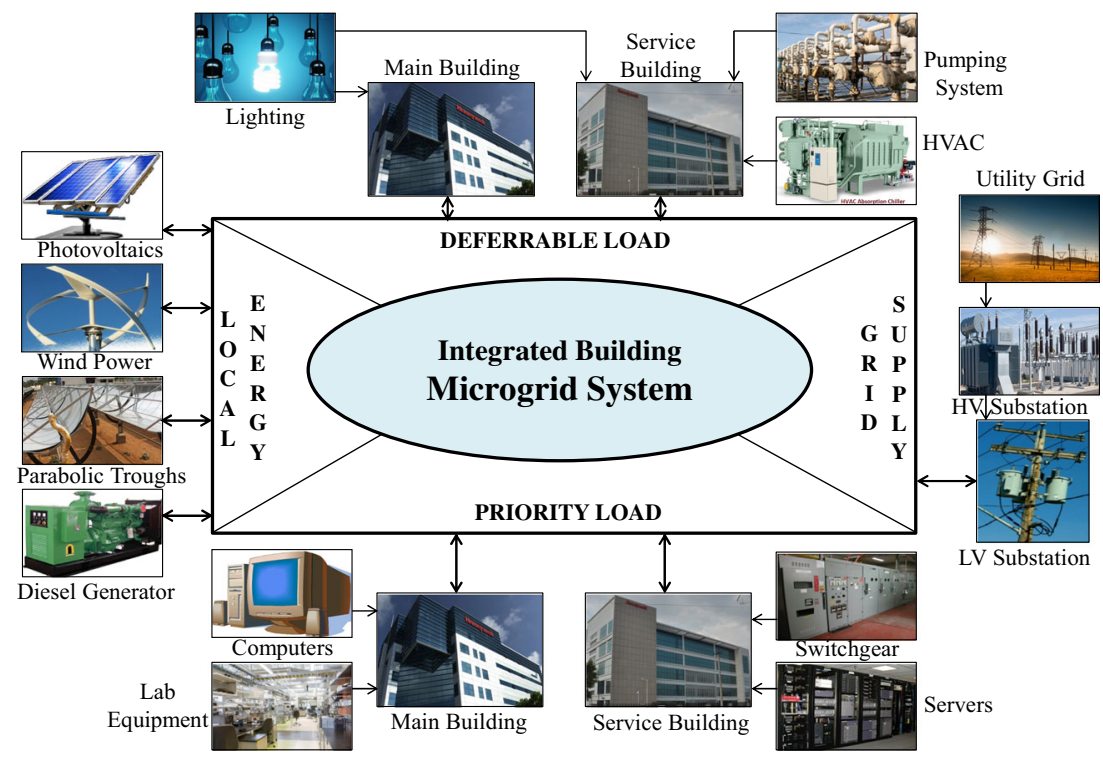

Laptop Units Modeling

These units does not require much time and energy to shut down or start. But, once connected, they function for nearly 8$10 \mathrm{~h}$ in a day and vary based on application. Condition for laptop on/off is given by (7). Minimum required operation time is given by (8) and (9). Maximum consecutive operation intervals is shown by (10).

$r_{l p t}(t-1)-r_{l p t}(t) \geq x_{l p t}(t), \quad \forall t \in T_{l p t}$

$D_{l p t}^{r o t}=\sum_{t \in T_{l p t}} r_{l p t}(k), \quad \forall t \in T_{l p t}$

$\sum_{k=t-x_{l p t}+1}^{t} x_{l p t}(t) \leq r_{l p t}(t), \quad \forall t \in\left[\varepsilon_{l p t}+x_{l p t}+1, L t_{l p t}\right]$

$t+D^{m s t}$

$\sum_{k=t} r_{l p t}(k) \leq N\left(1-x_{l p t}(t)\right)+D_{l p t}^{m s t}, \quad \forall t \in T_{l p t}$

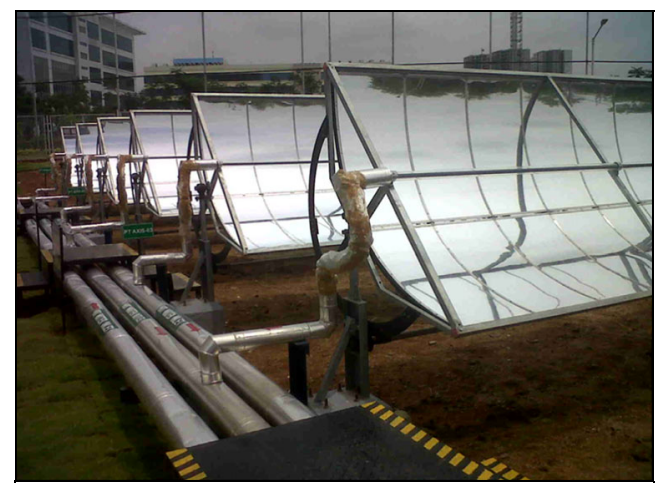

Fig. 9 Solar Parabolic Troughs (PT) array

\section{Lighting Units Modeling}

Lighting is one of the important constituent of an urban building to be considered, where the most of the energy is consumed. In the present urbanization scenario, there is no enough natural ventilation for the daily survival. It necessitates to illuminate the lighting resources for most of the time in a day for both inside and as well as for surroundings. The lighting unit operates based on (11).

$$
\left(1+F_{t}\right) f_{a}^{\max }(t) \geq l_{a}(t)+f_{a}^{\min }(t)
$$

Where, $l_{a}(t)$ is the illumination created by the lighting unit in area ' $a$ ' in time ' $t$ '; $f_{a}^{\max }(t)$ and $f_{a}^{\min }(t)$ are the minimum and maximum required illumination at time ' $t$ ' respectively; $F_{t}$ is the coefficient of price elasticity $\left(0 \leq F_{t} \leq 1\right)$.

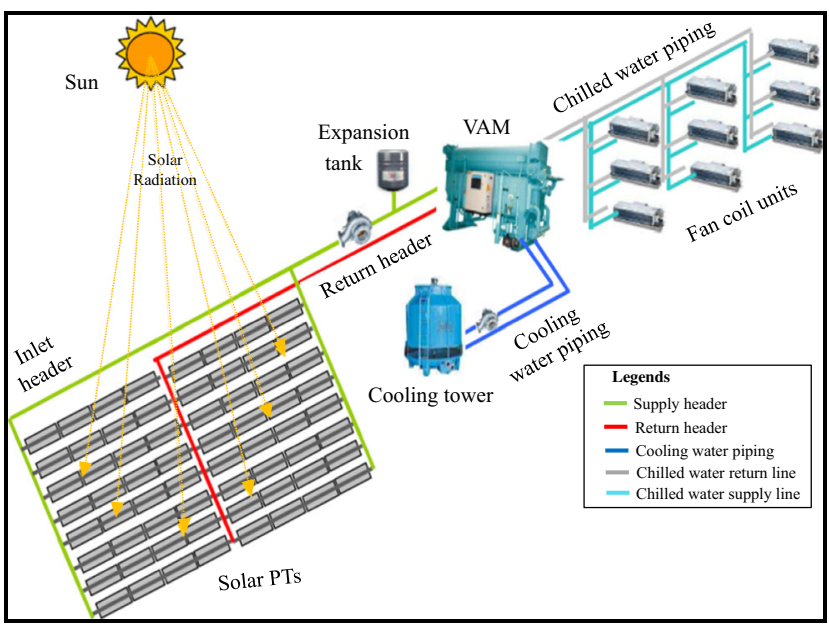

Fig. 10 Solar based cooling system schematic 


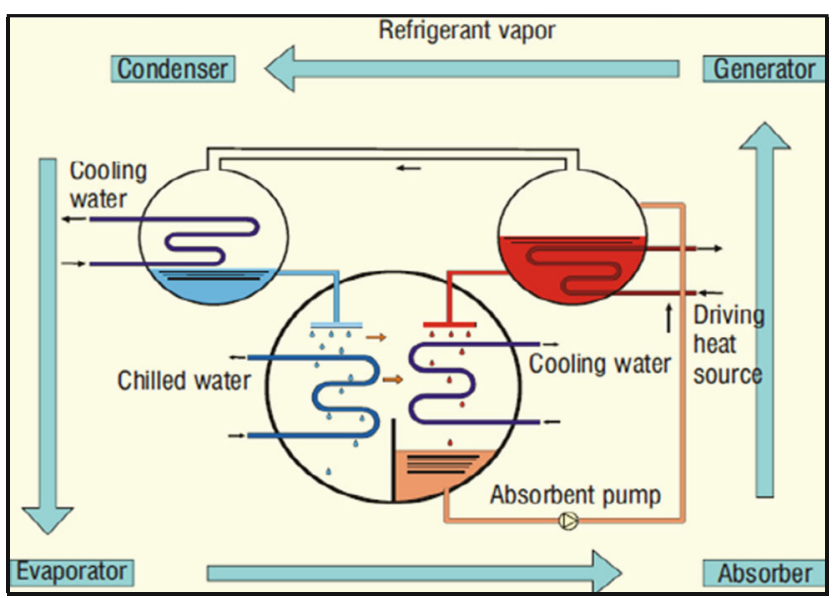

Fig. 11 Vapour Absorption Machine (VAM) System

\section{Lab Equipment and Servers Modeling}

Lab equipment and servers are seasonal equipment that continuously operates throughout the year and can be switched off in case of maintenance. So, it's down time is negligible when compared with running time. These units operates based on (12)-(15).

$$
\begin{aligned}
& r_{i}(t)-r_{i}(t-1)=x_{i}(t)-y_{i}(t), \quad \forall t \in T_{i} \\
& y_{i}(t)+x_{i}(t)=1, \quad \forall t \in T_{i} \\
& \sum_{j \in T_{i}} r_{i}(n)=D_{i}^{r o t} \\
& \sum_{n=t}^{j} D_{i}^{m s t}+N\left(1-x_{i}(t)\right) \geq x_{i}(t), \quad \forall t \in T_{i}
\end{aligned}
$$

Where, ' $i$ ' represents ser/lbe.

\section{Pumping Units Modeling}

The operation of these units depend on (16)-(20). Condition whether the units are on/off is given by (16). Required time of operation is given by (17). Minimum uptime and downtime is

Table 3 Solar thermal system modeling parameters

\begin{tabular}{ll}
\hline Parameter & Values \\
\hline Cooling capacity & $100 \mathrm{TR}$ \\
Number of PTs required & 128 \\
Hot water inlet temperature to VAM & $165{ }^{\circ} \mathrm{C}$ \\
Hot water return temperature from VAM & $145{ }^{\circ} \mathrm{C}$ \\
Cooling water supply temperature & $32{ }^{\circ} \mathrm{C}$ \\
Cooling water outlet temperature & $37.3{ }^{\circ} \mathrm{C}$ \\
Chilled water inlet / outlet temperature & $12 / 10{ }^{\circ} \mathrm{C}$ \\
Power supply & $415 \mathrm{~V}, 50 \mathrm{~Hz}, 3 \phi$ \\
Power consumption & $7.6 \mathrm{kVA}$ \\
\hline
\end{tabular}

Table 4 WP unit specifications for $1 \mathrm{~kW}$

\begin{tabular}{lc}
\hline Parameter & Values \\
\hline Turbine parameters (Type: vertical axis wind turbine) \\
Wind speed at start-up & $2.6 \mathrm{~m} / \mathrm{s}$ \\
Wind speed (cut-in) & $3.6 \mathrm{~m} / \mathrm{s}$ \\
Wind speed (cut-out) & $25 \mathrm{~m} / \mathrm{s}$ \\
Rated wind speed & $12 \mathrm{~m} / \mathrm{s}$ \\
Max (survival) wind speed & $50 \mathrm{~m} / \mathrm{s}$ \\
Generator parameters (Synchronous, permanent magnet, 3申, 16 poles) \\
Rated voltage & $270 \mathrm{~V}$ \\
Rated temperature & $<55^{\circ} \mathrm{C}$ \\
Revolutions per minute & $120 \mathrm{RPM}$ \\
Capacity & $1 \mathrm{~kW}$ \\
\hline
\end{tabular}

given by (18) and (19) respectively. Maximum number of successive operation time intervals is given by (20).

$x_{\text {pum }}(t) \geq r_{\text {pum }}(t)-r_{\text {pum }}(t-1), \quad \forall t \in T_{\text {pum }}$

$\sum_{t \in T_{\text {pum }}} r_{\text {pum }}(k)=D_{\text {pum }}^{\text {rot }}, \quad \forall t \in T_{\text {pum }}$

$\sum_{k=t-M u_{p u m}+1}^{t} x_{p u m}(t) \leq r_{p u m}(t), \forall t \in\left[\varepsilon_{p u m}+M u_{p u m}+1, L t_{p u m}\right]$

$\sum_{k=t-M d_{p u m}+1}^{t} x_{p u m}(t) \leq 1-r_{p u m}\left(t-M d_{p u m}\right), \forall t \in\left[\varepsilon_{p u m}+M d_{p u m}+1, L t_{p u m}\right]$

$\sum_{k=t}^{t+D_{\text {pum }}^{m s t}} r_{\text {pum }}(k) \leq D_{\text {pum }}^{m s t}+N\left(1-x_{\text {pum }}(t)\right), \quad \forall t \in T_{\text {pum }}$

\section{PV and WP Units Modeling}

The batteries are getting charged from the energy of PV and WP and discharged to the distribution system. Condition for charging of a battery through PV and WP is given by (21). Battery energy storage (discharge/charge) status at time ' $t$ ' based on ' $t-1$ ' is given by (22). The battery drain

Table 5 PV Unit Specifications for $1 \mathrm{~kW}$

\begin{tabular}{ll}
\hline Parameter & Values \\
\hline Overall average capacity of PV & $1 \mathrm{~kW}$ \\
Voltage at maximum power $\left(V_{m p}\right)$ & $29.6 \mathrm{~V}$ \\
Current at maximum power $\left(I_{m p}\right)$ & $7.8 \mathrm{~A}$ \\
Open circuit voltage & $37 \mathrm{~V}$ \\
Series fuse rating & $15 \mathrm{~A}$ \\
Weight of each panel & $22 \mathrm{Kg}$ \\
\hline
\end{tabular}




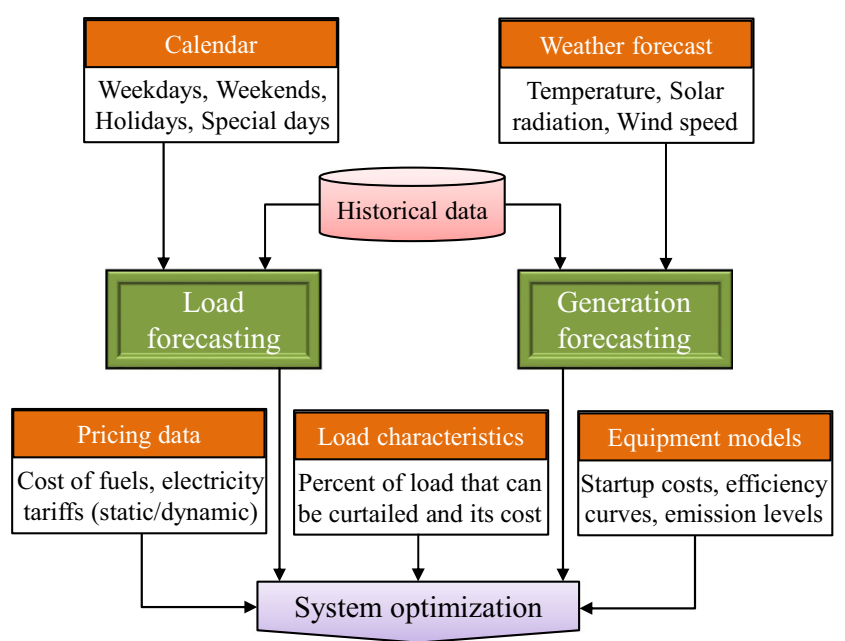

Fig. 12 Input profiles feeding to optimization scheme

equation is given by (23). Charging or discharging of the battery does not happen simultaneously and are related with (24). Tables 4 and 5 gives the WP and PV design specifications respectively.

$$
\begin{aligned}
& C h_{i}(t)=\left\{\begin{array}{lll}
P_{i} & \text { if } & P_{i}(t) \leq P_{i}^{c h r} \\
P_{i}^{c h r} & \text { if } & P_{i}(t) \geq P_{i}^{c h r}
\end{array}\right. \\
& e_{i}(t)=\tau\left[r_{i}^{c h r}(t) C h_{i}(t)-r_{i}^{d s r}(t) \bar{C}_{i}\right]+e_{i}(t-1) \\
& E_{i}^{\max } \geq e_{i}(t) \geq E_{i}^{\min }, \quad \forall t=T_{i} \\
& r_{i}^{c h r}(t)+r_{i}^{d s r}(t) \leq 1, \quad \forall t=T
\end{aligned}
$$

Where, ' $i$ ' represents $p v a / w t g$.

\section{Diesel Generator Unit Modeling}

The required operation time and condition of operation of diesel generator unit is shown by (25) and (26) respectively. Minimum up and down times to start and stop the diesel generator are given by (27) and (28)
Fig. 13 Flow chart for the system optimization

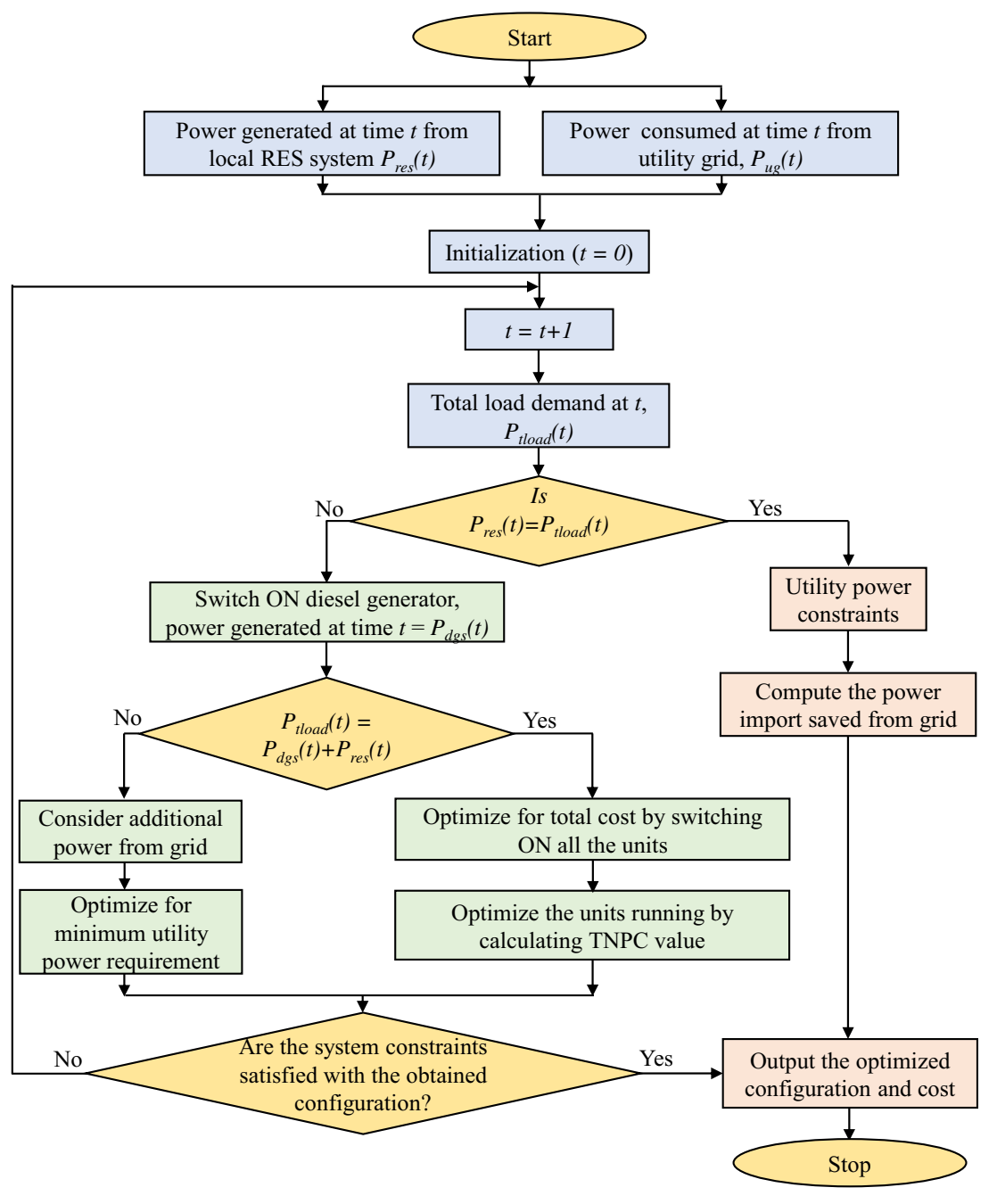


Fig. 14 Model for the simulation of the integrated building microgrid system

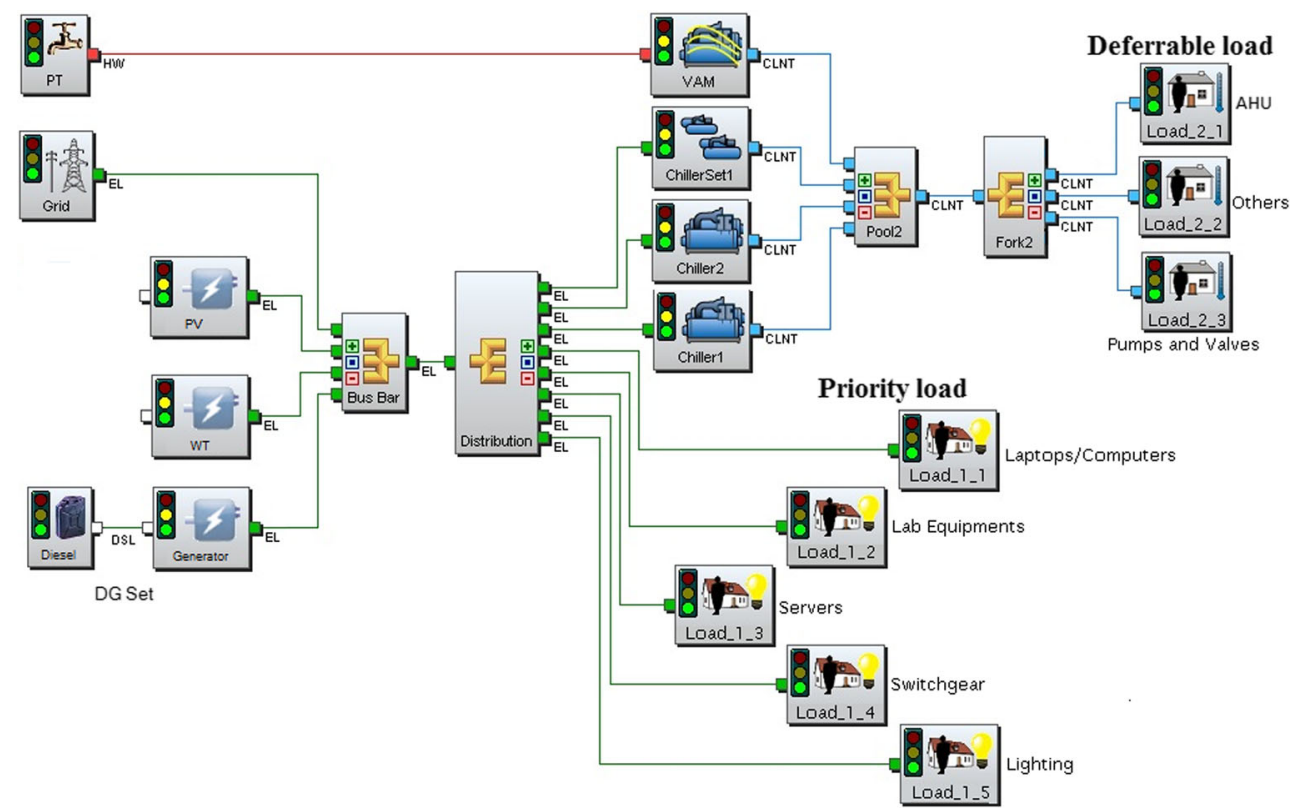

respectively with maximum number of successive operations given by (29).

$\sum_{t \in T_{d g s}} r_{d g s}(k)=D_{d g s}^{r o t}, \quad \forall t \in T_{d g s}$

$x_{d g s}(t) \geq r_{d g s}(t)-r_{d g s}(t-1), \quad \forall t \in T_{d g s}$

$\sum_{k=t-M u_{d g s}+1}^{t} x_{d g s}(t) \leq r_{d g s}(t), \quad \forall t \in\left[M u_{d g s}+\varepsilon_{d g s}+1, L t_{d g s}\right]$

$\sum_{k=t-M d_{d g s}+1}^{t} 1-r_{d g s}\left(t-M d_{d g s}\right) \geq x_{d g s}(t), \quad \forall t \in\left[M d_{d g s}+\varepsilon_{d g s}+1, L t_{d g s}\right]$

$\sum_{k=t}^{t+D_{d g s}^{m s t}} r_{d g s}(k) \leq N\left(1-x_{d g s}(t)\right)+D_{d g s}^{m s t}, \quad \forall t \in T_{d g s}$

\section{Procedure for the System Optimization}

The system optimization offers an economically ideal energy consumption profile by considering building facilities, equipment characteristics, and energy market conditions. The method used is a nonlinear quadratic programming method with sequential mixed inequality and equality constraints. This active set method divides the inequality constraints into two sets: active and inactive. Here, the inactive set is ignored and hence, the active set for every iteration is taken as the working set. Then, the new point is obtained by moving into the surface that is defined by active set.

The system objective function is to minimize the cost function (30) with respect to the constraints (31)-(34). The overall objective is to minimize the power supply from diesel generator, utility grid and meeting the overall load by maximizing renewable energy utilization.

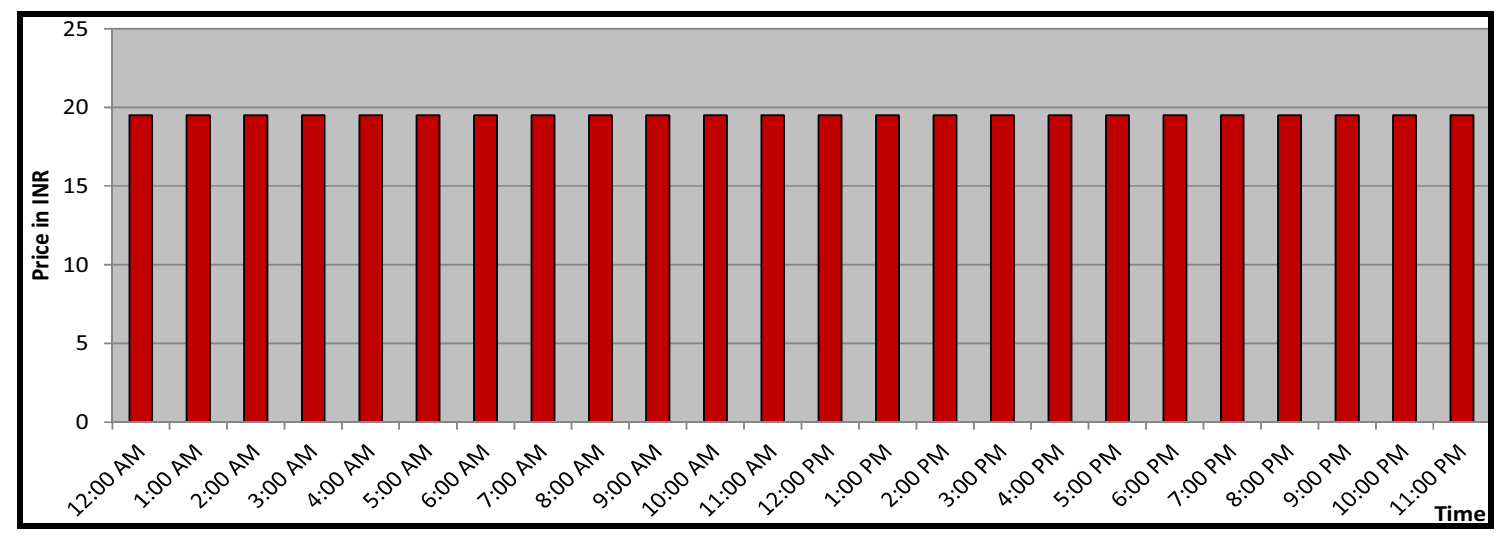

Fig. 15 Diesel generator forecasted supply price for unit 


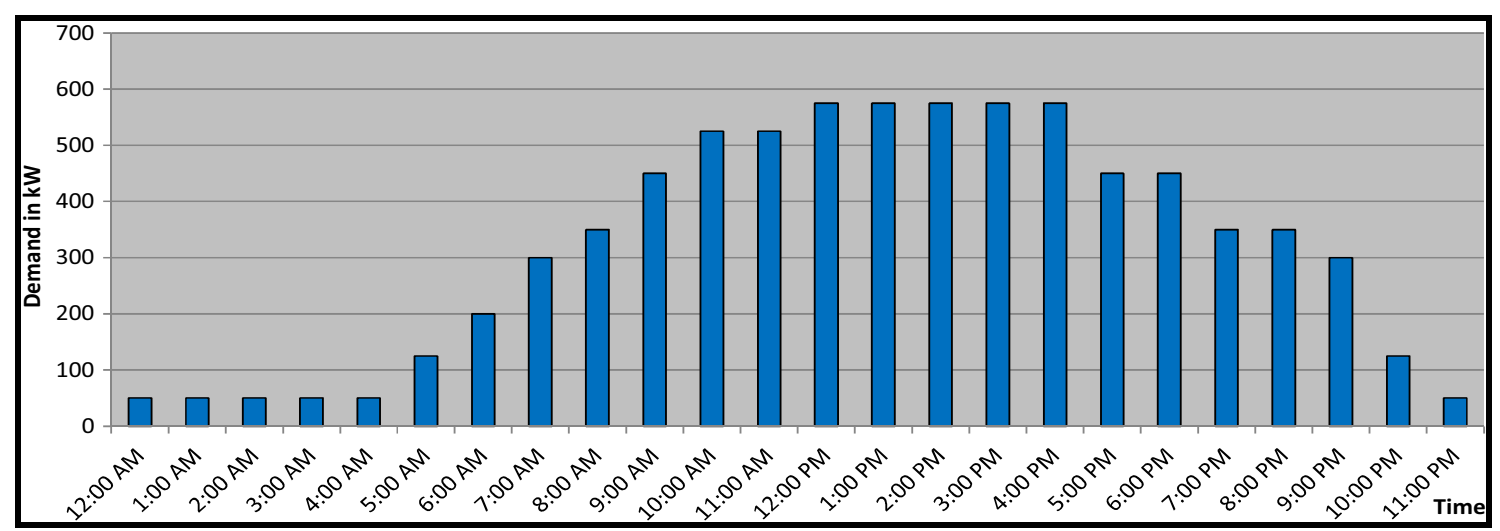

Fig. 16 Main building forecasted demand

$\min (G)=\min \left(G_{e m i} \lambda_{1}+G_{p d c} \lambda_{2}+G_{e c n} \lambda_{3}+G_{t e c} \lambda_{4}\right)$

Subject to

$P_{\text {tload }}(t)-\left(P_{\text {res }}(t)+P_{\text {dgs }}(t)+P_{\text {ug }}(t)\right) \leq 0$

$0 \leq P_{d g s}(t) \leq P_{d g s, \max }(t)$

$0 \leq P_{\text {ug }}(t) \leq P_{\text {ug, } \max }(t)$

Where,

$P_{r e s}(t)=P_{p v a}(t)+P_{w t g}(t)+P_{p t u}(t)$

Where, $G_{e m i}, G_{p d c}, G_{e c n}$, and $G_{t e c}$ represent the emission cost, peak demand charges, energy consumption, and total energy cost respectively. $\lambda_{1}, \lambda_{2}, \lambda_{3}, \lambda_{4}$ are the respective weights. $P_{\text {tload }}(t)$ indicates the total load, $P_{\text {res }}(t)$ indicates the total RES energy available, $P_{\text {dgs }}(t)$ indicates the total diesel generator output, and $P_{u g}(t)$ indicates the total utility power taken from the grid, $P_{d g s, \max }(t)$ and $P_{u g, \max }(t)$ are the maximum allowed diesel generator and utility grid supplies respectively as given in Table 8 , at time ' $t$ '.

Figure 12 shows the typical input profiles required to develop the optimization scheme. Figure 13 shows the optimization scheme. This scheme manages the available energy resources to meet the load demand at every instant. The overall building power system model is shown in Fig. 14.

\section{Simulation Results}

The simulation results differentiate the current architecture of the building power system with the proposed microgrid architecture in terms of economy. Figure 15 shows diesel generator supply price. The demands on main and service buildings are given by Figs. 16 and 17 respectively. The grid supply price is constant in a day as shown in Fig. 18.

Based on all these inputs, the overall energy cost for conventional and microgrid system are calculated at each hour of a day as shown in Figs. 19 and 20 with the corresponding cumulative results shown by Tables 6 and 7 respectively.

The overall burden of the building power system is primarily supplied by utility grid system in the conventional method, which can be seen in Table 6. In the

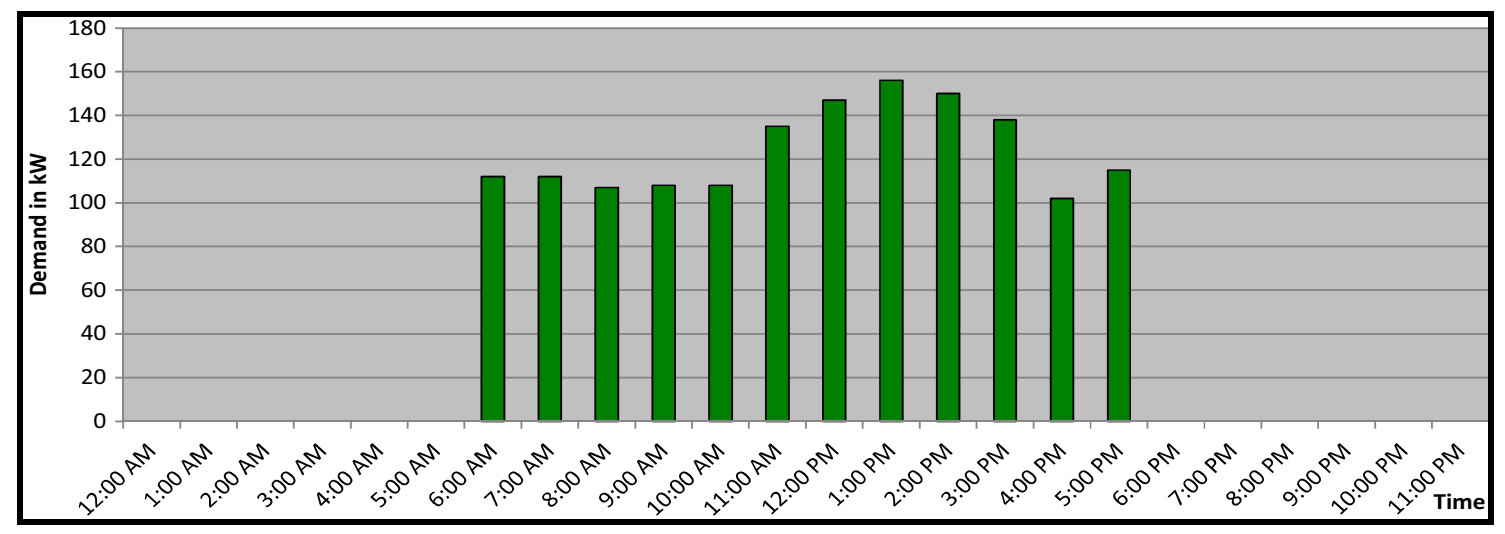

Fig. 17 Service building forecasted demand 


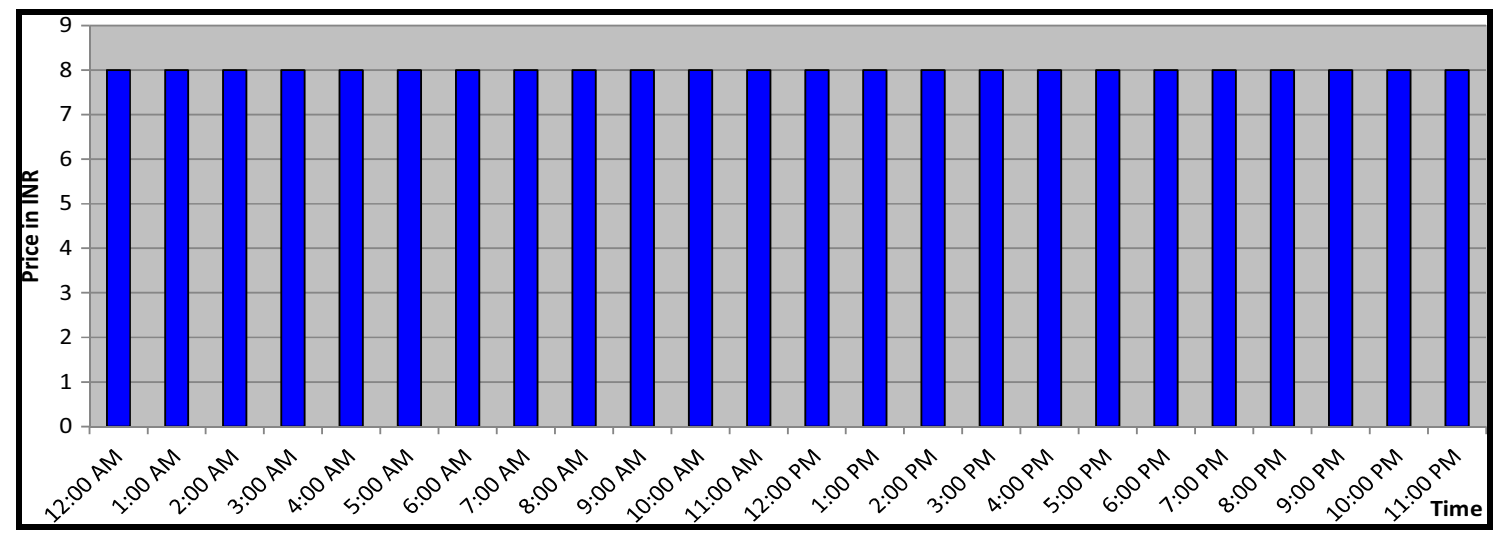

Fig. 18 Grid supply price per unit

case of microgrid system, along with the utility grid, the PV, PT, WP systems will also supply the load requirements of the building.

In either case, the diesel generator will only act under the case of grid failures, emergencies, or insufficient power supply from utility grid, local power generation, and storage reserves.

Based on these simulation results, the net savings and return on investment with the microgrid are calculated as follows.

\section{Total Cost Savings Calculations}

The total energy cost per a day for conventional system $=$ Rs. 95560.12/- (Sum of column-2 in Table 6).

The total energy cost per a day for the microgrid system $=$ Rs. 69231.86 /- (Sum of column-2 in Table 7).

Hence, the total energy savings per day can be obtained as; Energy savings = Rs. $95560.12-$ Rs. $69231.86=$ Rs. 26328.26

Savings Percentage $=\frac{26328.26}{95560.12} \times 100=27.55 \%$

\section{Total Net Present Cost (TNPC) Calculations}

Total net present cost (TNPC) of the system is the combination of total installation and operation cost in its life span. The objective of calculating TNPC is to identify best economic combination of the components to form the microgrid. So, the objective function is to have low TNPC for the system [28]. It is calculated as shown in (35)-(36).

$$
\begin{aligned}
& \min \left(\sum T N P C\left(C_{i}\right)\right) \\
& \quad=\min \left(\sum\left(N_{i} \times\left(\text { CplC }_{i}+\left(R p l C_{i} \times P_{i}\right)+\frac{O \& M C_{i}}{C R F}\right)\right)\right) \\
& C R F=\frac{I_{r}\left(1+I_{r}\right)^{T}}{\left(1+I_{r}\right)^{T}-1}
\end{aligned}
$$

Where, ' $i$ ' indicates the component type-PV, PT, WP, diesel generator, battery, and converter; $C_{i}$ is the overall system annualized cost that includes component's procurement, operation, replacement, and fuel maintenance; $P_{i}$ is the present single payment worth of a component; $N_{i}$ is the number of total system components; $\mathrm{CplC}_{i}$ is the component's capital

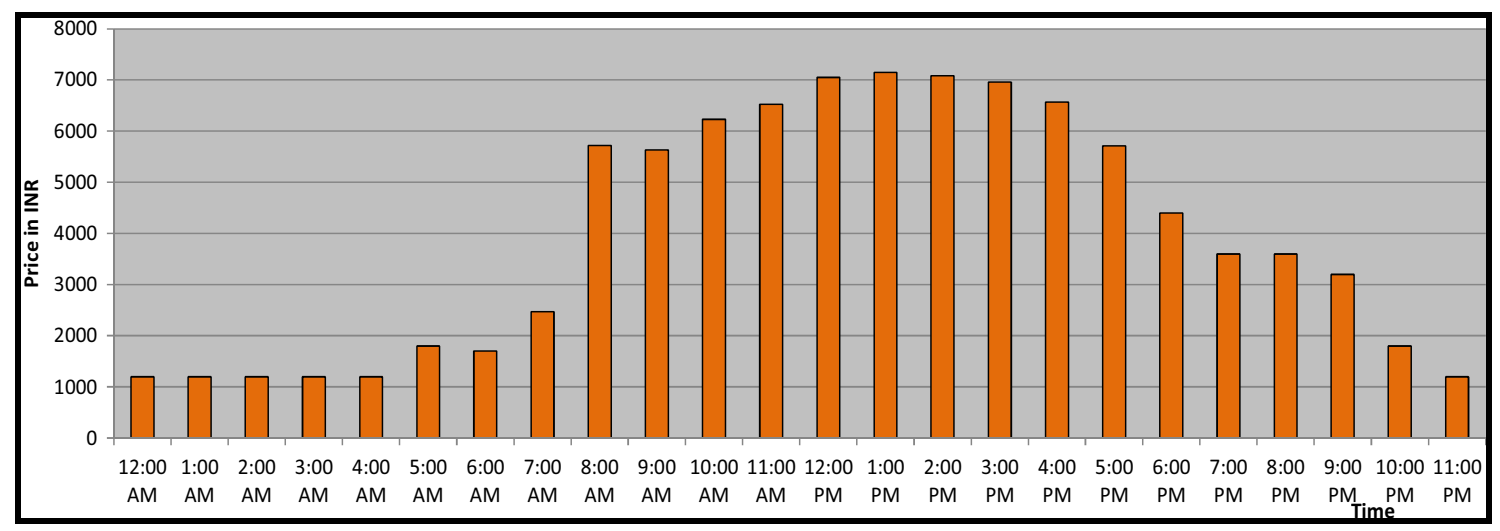

Fig. 19 Total energy cost in a day for conventional power system 


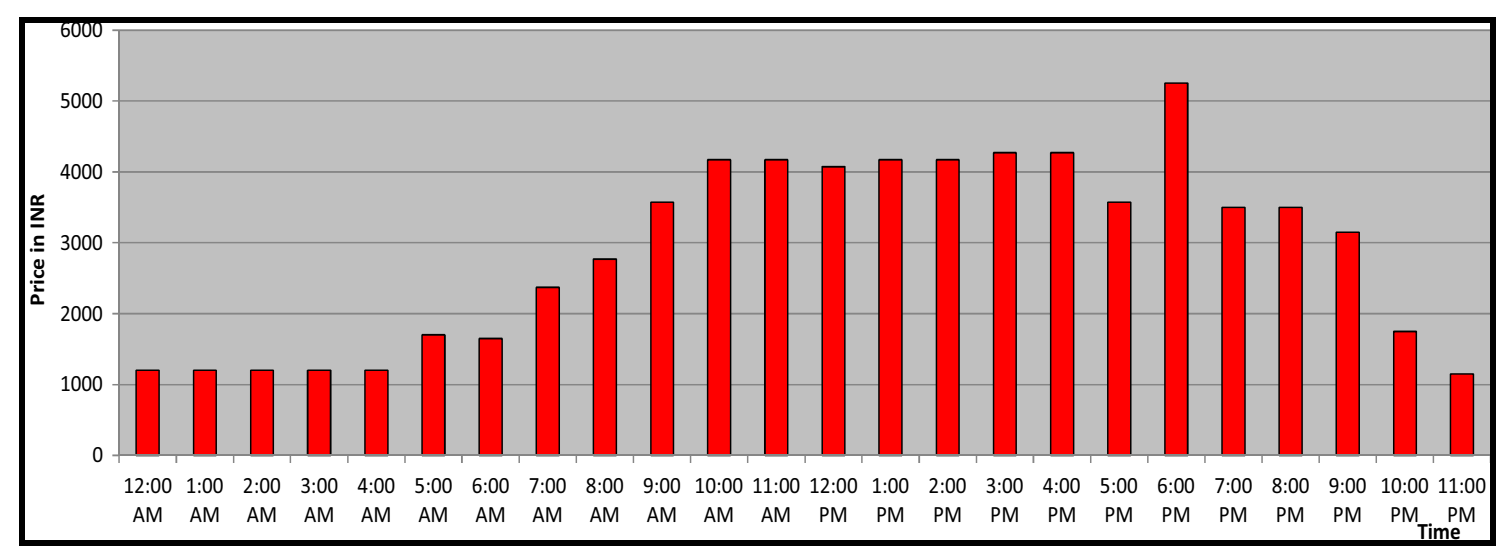

Fig. 20 Total energy cost in a day for retrofitted microgrid system

cost; $R p l C_{i}$ is the component's replacement cost; $O \& M C_{i}$ is the component's operation and maintenance cost; $T$ indicates project lifetime; $C R F$ indicates capital recovery factor; and $I_{r}$ indicates annual interest rate during the project execution.

In order to perform the TNPC calculations, ranges of all the microgrid components are varied to a certain limits as shown in the Table 8 and the corresponding TNPC is calculated.
Lower TNPC value is given with higher rank and arranged the table in the corresponding order as shown in Table 9. The other parameters such as system constraints and economics are considered as follows for the TNPC calculations.

1. $7 \%$ operating reserve is considered in the total demand. And it is taken as $20 \%$ for each wind and solar output.

Table 6 Conventional power system cost of energy

\begin{tabular}{|c|c|c|c|c|c|c|c|c|}
\hline Time of a day & Total cost (INR) & Utility grid (kW) & Diesel generator $(\mathrm{kW})$ & Chiller (kW) & VAM (kW) & PT & $\mathrm{PV}(\mathrm{kW})$ & $\mathrm{WP}(\mathrm{kW})$ \\
\hline 12:00 AM & 1200 & 50 & Off & Off & Off & Off & Off & Off \\
\hline 1:00 AM & 1200 & 50 & Off & Off & Off & Off & Off & Off \\
\hline 2:00 AM & 1200 & 50 & Off & Off & Off & Off & Off & Off \\
\hline 3:00 AM & 1200 & 50 & Off & Off & Off & Off & Off & Off \\
\hline 4:00 AM & 1200 & 50 & Off & Off & Off & Off & Off & Off \\
\hline 5:00 AM & 1800 & 125 & Off & Off & Off & Off & Off & Off \\
\hline 6:00 AM & 1702 & 300 & Off & Off & Off & Off & Off & Off \\
\hline 7:00 AM & 2471.17 & 400 & Off & Off & Off & Off & Off & Off \\
\hline 8:00 AM & 5720.68 & 502.585 & Off & Off & Off & Off & Off & Off \\
\hline 9:00 AM & 5631.75 & 603.969 & Off & Off & Off & Off & Off & Off \\
\hline 10:00 AM & 6231.75 & 678.969 & Off & Off & Off & Off & Off & Off \\
\hline 11:00 AM & 6525.69 & 715.712 & Off & Off & Off & Off & Off & Off \\
\hline 12:00 PM & 7052.81 & 781.601 & Off & Off & Off & Off & Off & Off \\
\hline 1:00 PM & 7146.53 & 793.316 & Off & Off & Off & Off & Off & Off \\
\hline 2:00 PM & 8245.99 & 915.526 & Off & Off & Off & Off & Off & Off \\
\hline 3:00 PM & 6957.69 & 769.712 & Off & Off & Off & Off & Off & Off \\
\hline 4:00 PM & 6565.15 & 720.644 & Off & Off & Off & Off & Off & Off \\
\hline 5:00 PM & 5708.91 & 613.614 & Off & Off & Off & Off & Off & Off \\
\hline 6:00 PM & 4400 & 450 & Off & Off & Off & Off & Off & Off \\
\hline 7:00 PM & 3600 & 350 & Off & Off & Off & Off & Off & Off \\
\hline 8:00 PM & 3600 & 350 & Off & Off & Off & Off & Off & Off \\
\hline 9:00 PM & 3200 & 300 & Off & Off & Off & Off & Off & Off \\
\hline 10:00 PM & 1800 & 125 & Off & Off & Off & Off & Off & Off \\
\hline 11:00 PM & 1200 & 50 & Off & Off & Off & Off & Off & Off \\
\hline
\end{tabular}


Table 7 Microgrid system cost of energy

\begin{tabular}{|c|c|c|c|c|c|c|c|c|}
\hline Time of a day & Total cost (INR) & Utility grid $(\mathrm{kW})$ & Diesel generator $(\mathrm{kW})$ & Chiller $(\mathrm{kW})$ & VAM $(\mathrm{kW})$ & PT & PV $(\mathrm{kW})$ & $\mathrm{WP}(\mathrm{kW})$ \\
\hline 12:00 AM & 1200 & 50 & Off & 0 & Off & Off & Off & On \\
\hline 1:00 AM & 1200 & 50 & Off & 0 & Off & Off & Off & On \\
\hline 2:00 AM & 1200 & 50 & Off & 0 & Off & Off & Off & On \\
\hline 3:00 AM & 1200 & 50 & Off & 0 & Off & Off & Off & On \\
\hline 4:00 AM & 1200 & 50 & Off & 0 & Off & Off & Off & On \\
\hline 5:00 AM & 1700 & 125 & Off & 0 & Off & Off & Off & On \\
\hline 6:00 AM & 1650 & 200 & Off & Off & 112 & On & On & On \\
\hline 7:00 AM & 2371.03 & 300 & Off & Off & 112 & On & On & On \\
\hline 8:00 AM & 2771.02 & 350 & Off & Off & 107 & On & On & On \\
\hline 9:00 AM & 3571.02 & 450 & Off & Off & 108 & On & On & On \\
\hline 10:00 AM & 4171.02 & 525 & Off & Off & 108 & On & On & On \\
\hline 11:00 AM & 4171.11 & 525 & Off & Off & 135 & On & On & On \\
\hline 12:00 PM & 4071.17 & 575 & Off & Off & 147 & On & On & On \\
\hline 1:00 PM & 4171.16 & 575 & Off & Off & 156 & On & On & On \\
\hline 2:00 PM & 4171.16 & 575 & Off & Off & 150 & On & On & On \\
\hline 3:00 PM & 4271.13 & 575 & Off & Off & 138 & On & On & On \\
\hline 4:00 PM & 4271.01 & 575 & Off & Off & 102 & On & On & On \\
\hline 5:00 PM & 3571.03 & 450 & Off & Off & 115 & On & On & On \\
\hline 6:00 PM & 5250 & 450 & Off & 0 & Off & Off & Off & On \\
\hline 7:00 PM & 3500 & 350 & Off & 0 & Off & Off & Off & On \\
\hline 8:00 PM & 3500 & 350 & Off & 0 & Off & Off & Off & On \\
\hline 9:00 PM & 3150 & 300 & Off & 0 & Off & Off & Off & On \\
\hline 10:00 PM & 1750 & 125 & Off & 0 & Off & Off & Off & On \\
\hline 11:00 PM & 1150 & 50 & Off & 0 & Off & Off & Off & On \\
\hline
\end{tabular}

2. Minimum renewable fraction is taken as $37.5 \%$. It indicates that at any point of time the minimum available energy from renewables shall be $37.5 \%$ of the total energy consumed at that moment.

3. Lifetime of the establishment is taken as 20 years with an interest rate of $6 \% /$ annum.

4. Diesel generator installation cost and land cost for the project deployment are ignored, as these are already available at the considered location in the case study.

\section{Return on Investment (RoI) Calculations}

From the Table 9, it is observed that the optimal system configuration is obtained with TNPC of 57457221 INR for year. Hence, the RoI can be calculated as follows.

$\mathrm{RoI}=\frac{\mathrm{TNPC}}{\text { Savings per day }}=\frac{57457221}{26328.26}$
$\therefore \mathrm{RoI}=2182.34$ Days $=5.97$ Years

Table 8 Considerations for Calculating TNPC

\begin{tabular}{llll}
\hline Component & Allowed range & $\begin{array}{l}\text { Capital cost (including fuel, operation } \\
\text { \& maintenance cost) }\end{array}$ & Life time \\
\hline PV & $75 \mathrm{~kW}$ to $150 \mathrm{~kW}$ & $215775 \mathrm{INR} / \mathrm{kW}$ & $25 \mathrm{years}$ \\
$\mathrm{WP}$ & $75 \mathrm{~kW}$ to $150 \mathrm{~kW}$ & $228721 \mathrm{INR} / \mathrm{kW}$ & $25 \mathrm{years}$ \\
$\mathrm{PT}$ & 50 to 150 & $66406 \mathrm{INR} / \mathrm{PT}$ & 20 years \\
VAM and chillers & $64 \mathrm{~kW}$ to $192 \mathrm{~kW}$ & $49040 \mathrm{INR} / \mathrm{kW}$ & 20 years \\
Diesel generator set & $0 \mathrm{~kW}$ to $2490 \mathrm{~kW}$ & $19.5 \mathrm{INR} / \mathrm{kW}$ (Already installed in the & $15 \mathrm{~K}$ operating hours \\
Bi-directional converter & $75 \mathrm{~kW}$ to $150 \mathrm{~kW}$ & building. So, installation cost is excluded) & 20 years \\
Battery & 0 to $120 \mathrm{kWh}(\mathrm{each}$ unit of & $77.2 \mathrm{INR} / \mathrm{kW} / \mathrm{kWh}$ & 10 years \\
Utility grid & $12 \mathrm{~V}, 200 \mathrm{Ah}, 2.4 \mathrm{kWh})$ & $8 \mathrm{INR} / \mathrm{kW}$ & \\
\hline
\end{tabular}


Table 9 Total net present cost calculations

\begin{tabular}{|c|c|c|c|c|c|c|c|c|}
\hline PV $(\mathrm{kW})$ & WP (kW) & PT & VAM and chillers & DG (kW) & Converter $(\mathrm{kW})$ & Battery (kWh) & Utility grid (kW) & TNPC (INR) \\
\hline 150 & 39 & 128 & 156 & 0 & 150 & 120 & 575 & 57457221 \\
\hline 95 & 94 & 128 & 156 & 0 & 150 & 120 & 575 & 58169251 \\
\hline 100 & 89 & 128 & 156 & 0 & 150 & 120 & 575 & 58284202 \\
\hline 150 & 110 & 112 & 135 & 0 & 150 & 120 & 525 & 71603676 \\
\hline 130 & 130 & 112 & 135 & 0 & 150 & 120 & 525 & 71862596 \\
\hline 110 & 150 & 112 & 135 & 0 & 150 & 120 & 525 & 72121516 \\
\hline 150 & 150 & 88 & 107 & 163 & 150 & 120 & 350 & 77787430 \\
\hline 150 & 150 & 93 & 112 & 208 & 150 & 120 & 300 & 78365138 \\
\hline 150 & 150 & 93 & 112 & 420 & 150 & 120 & 200 & 78368472 \\
\hline
\end{tabular}

\section{Conclusions}

This paper explained the challenges and opportunities for the development of green microgrids in Indian scenario. Various government initiatives calling for green and sustainable energy deployments are drafted. In order to perform feasibility analysis, a practical case study is considered. From the analysis, it can be observed that the microgrid implementation leads to an average energy savings of Rs. $26328.26(27.55 \%)$ per day with RoI of 5.97 years.

These integration schemes save energy usage, reduces environmental pollutions and supports the current trend "green building" initiatives and as well as cumulatively reduces burden on utility grid. This reduces frequent grid outages and useful as an alternative to fast depleting conventional fossil fuel energy.

The architecture and the analysis presented in this paper can be applicable for any critical urban community building such as buildings in greater communities, financial districts, industrial zones, and universities.

\section{Future Directions}

This paper mainly focused on describing the benefits of installing RES based microgrids at urban buildings. The feasibility analysis is presented with a practical case study. However, below mentioned concept can be considered as future work in order to enhance the design capabilities of microgrids in a more economical way for a specific location.

- Based on type of loads (AC or DC) and RES availability (AC or DC), it is required to choose more suitable architecture of the microgrid among the following.

- Central AC-bus architecture

- Central DC-bus architecture
- Hybrid (AC and DC)-bus architecture.

- Distributed AC-bus architecture

The selection of proper architecture will play a major role in order to generate clean, economic, and quality power. So, in this aspect, the method presented in this paper can be extended with respect to more suitable architecture based on the usage scenario.

\section{References}

1. Jaganmohan Reddy Y, Pavan Kumar YV, Padma Raju K, Ramsesh A (2012) Retrofitted hybrid power system design with renewable energy resources for buildings. Proc IEEE Trans Smart Grid 3(4): 2174-2187

2. Bozchalui MC, Hashmi SA, Hassen H (2012) Optimal operation of residential energy hubs in smart grids. Proc IEEE Trans Smart Grid 3(4):1755-1766

3. Nelson DB, Nehrir MH, Wang C (2006) Unit sizing and cost analysis of stand-alone hybrid wind/PV/fuel cell power generation systems. Proc Elsevier J Renew Energy 31(10):1641-1656

4. Pushkar S, Becker R, Katz A (2005) A methodology for design of environmentally optimal buildings by variable grouping. Proc Elsevier J Build Environ 40(8):1126-1139

5. Li Q, Xu Z, Yang L (2014) Recent advancements on the development of microgrids. Proc Springer J Modern Power Syst Clean Energy 2(3):206-211

6. Zhang H, Zhao D, Gu C, Li F, Wang B (2014) Economic optimization of smart distribution networks considering realtime pricing. Proc Springer J Modern Power Syst Clean Energy 2(4):350-356

7. Wang C, Jiao B, Guo L, Yuan K, Sun B (2014) Optimal planning of stand-alone microgrids incorporating reliability. Proc Springer J Modern Power Syst Clean Energy 2(3):195-205

8. Zhang L, Barakat G, Yassine A (2012) Deterministic optimization and cost analysis of hybrid pv/wind/battery/diesel power system. Proc Int J Renew Energy Res 2(4):686-696

9. Mohsenian AH, Garcia AL (2010) Optimal residential load control with price prediction in real-time electricity pricing environments. Proc IEEE Trans Smart Grid 1(2):120-133 
10. Emiliano D, Hao Z, Giannakis GB (2013) Distributed optimal power flow for smart microgrids. Proc IEEE Trans Smart Grid 4(3): 1464-1475

11. Bansal AK, Kumar R, Gupta RA (2013) Economic analysis and power management of a small autonomous hybrid power system using biogeography based optimization algorithm. Proc IEEE Trans Smart Grid 4(1):638-648

12. Kellogg WD, Nehrir MH, Gerez V (1998) Generation unit sizing and cost analysis for stand-alone wind, photovoltaic, and hybrid wind/pv systems. Proc IEEE Trans Energy Convers 13(1):70-75

13. Saif A, Ravikumar Pandi V, Zeineldin HH, Kennedy S (2013) Optimal allocation of distributed energy resources through simulation-based optimization. Proc Elsevier J Electr Power Syst Res 104:1-8

14. Pavlos SG, Hatziargyriou ND (2013) Optimal distributed generation placement in power distribution networks: models, methods, and future research. Proc IEEE Trans Power Syst 28(3):3420-3428

15. Omar H, Bhattacharya K (2012) Optimal planning and design of a renewable energy based supply system for microgrids. Proc Elsevier J Renew Energy 45:7-15

16. Installed capacities in India, Released by Central Electricity Authority, Ministry of Power, Government of India, 30th April 2014. http://www.cea.nic.in/reports/monthly/inst capacity/apr14. pdf

17. Load Generation Balance Report for 2014-15, Released by Central Electricity Authority, Ministry of Power, Government of India, May 2014. http://www.cea.nic.in/reports/yearly/lgbr_report.pdf

18. (2011) Scheme on off-grid and decentralized solar applications, Jawaharlal Nehru National Solar Mission developed by MNRE. http://mnre.gov.in/file-manager/UserFiles/jnnsm_ formats_st.pdf

19. (2013) Smart grid vision and roadmap for India, Published by ISGF. http://indiasmartgrid.org/en/Lists/News/Attachments/154/India\% 20Smart\%20Grid\%20Forum\%20Booklet.pdf

20. (2008) National Action Plan on Climate Change, Ministry of Environment, Forest, and Climate Change, Government of India. http://envfor.nic.in/ccd-napcc

21. NASA Atmospheric Science Data. https://eosweb.larc.nasa.gov/ cgi-bin/sse/grid.cgi?email=skip@larc.nasa.gov

22. The Electricity Act, 2003 (with amendments of 2003 and 2007). http://www.cercind.gov.in/electricty-act.html

23. National Electricity Policy. http://www.powermin.nic.in/whats new/national_electricity_policy.htm

24. Rajiv Gandhi Grameen Vidyutikaran Yojana. http://rggvy.gov.in/ rggvy/rggvyportal/rggvy_glance.html

25. Remote Village Electrification. http://www.mnre.gov.in/schemes/ offgrid/remote-village-electrification/

26. Rehtanz C (2010) Autonomous systems and intelligent agents in power system control and operation. Text book published by Springer

27. Pedrasa MA, Spooner TD (2010) Coordinated scheduling of residential distributed energy resources to optimize smart home services. Proc IEEE Trans Smart Grid 1(2):134-143

28. Pavan Kumar YV, Bhimasingu R (2015) Renewable energy based microgrid system sizing and energy management for green buildings. Proc Springer J Modern Power Syst Clean Energy 3(1):1-13

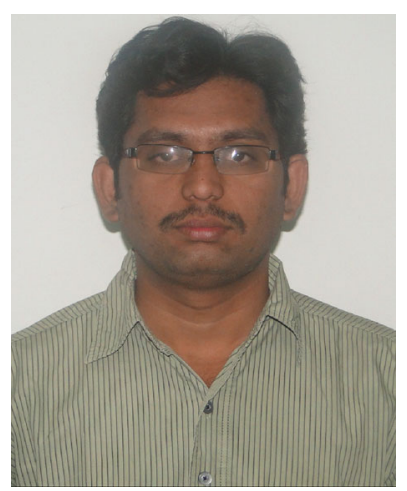

Y. V. Pavan Kumar (S'14) received B.Tech in Electrical and Electronics Engineering in 2007 from JNTUH University, India; M.Tech in Instrumentation and Control Systems in 2011 from JNTUK University, India; and currently pursuing Ph.D in Electrical Engineering in the area of Microgrids at Indian Institute of Technology Hyderabad (IITH), India. Prior to this, he has worked as a design engineer for Power and Control Systems, and Engineering Test Systems in the departments of $\mathrm{Au}-$ tomation and Control Solutions, Aerospace engineering, and Energy R\&D center of Honeywell Technology Solutions Lab, India for 3 years. He also has 2.5 years of teaching experience in Electrical and Electronics Engineering for undergraduate and postgraduate students. He has published 50 papers in International and National Journals and Conferences, 2 Books, 3 innovation disclosures through Honeywell. He has guided 6 M.Tech theses and 3 B.Tech theses. His research area includes Microgrids, Smartgrids, Advanced Control systems, and Artificial Intelligence. He is a member of IEEE Smart Grid Research \& Development (R\&D) Committee, student member of IEEE Power \& Energy Society, IEEE Communications Society, and IEEE Smart Grid Community. He is a reviewer for IEEE Transactions on Smart Grid and IEEE Industrial Electronics Transactions/Conferences.

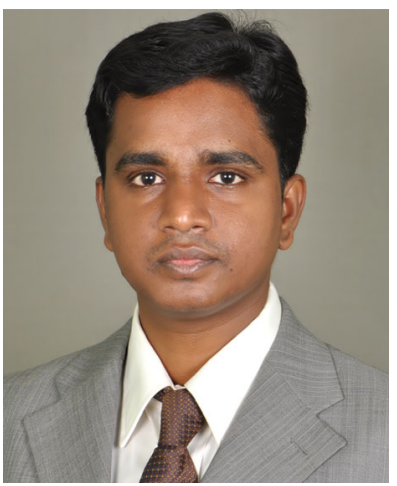

Bhimasingu Ravikumar obtained his B.Tech degree from Nagarjuna University, India in the year 2002; M.Sc (Engg.) and Ph.D both in the Department of Electrical Engineering, Indian Institute of Science (IISc), Bangalore, India in the year 2004 and 2009 respectively. After completion of his Ph.D, he worked as a Senior Research Associate and Junior Research Associate both at the Department of Electrical Engineering, IISc. Later he joined Global R\&D Center, Crompton Greaves Ltd., Mumbai, India as a Senior Executive-Technology and served for 3 years from 2010 to 2013. Currently, he is working as an Assistant Professor in the department of Electrical Engineering at Indian Institute of Technology Hyderabad (IITH), India. His research interests include AI techniques applications to power systems security improvement, computer-aided power system analysis and modeling, Power System protection and optimization, Wide Area Monitoring, and Control, and distribution system automation. He has guided 3 M.Tech theses and is currently guiding $2 \mathrm{M}$.Tech and $2 \mathrm{Ph} . \mathrm{D}$ students. He has authored 10 National and International Journal publications and 40 National and International Conference publications. He is a reviewer for IEEE Transactions on Power Delivery, IET Generation Transmission and Distribution Journal, Ain Shams Engineering Journal (ELSEVIER) and various reputed National and International Conferences. 